\section{EVALUATION OF PROVIDER PREFERENCES IN FIRST-LINE METASTATIC RENAL CELL CARCINOMA: COMPARISON BETWEEN DUAL IMMUNOTHERAPY VS. IMMUNOTHERAPY/TYROSINE KINASE INHIBITORS}

Priyanka Chablani ${ }^{*}$, Theodore Karrison, Walter Stadler. University of Chicago Medical Center, Chicago, IL, United States

Background Dual immunotherapy (ipilimumab/nivolumab, IO/ IO) and immunotherapy/tyrosine kinase inhibitor (IO/TKI) combinations (e.g. pembrolizumab/axitinib) are approved for first-line therapy of intermediate/poor risk metastatic renal cell carcinoma (RCC) ${ }^{1-4}$ but there is limited comparative data between these two options. We sought to understand how physicians decide between $\mathrm{IO} / \mathrm{IO}$ vs. IO/TKI for this indication.

Methods We sent a 10-question survey focused on a patient scenario of intermediate/poor risk metastatic RCC to 294 general and academic/disease-focused oncologists throughout the country using RedCAP software to solicit treatment preferences and rationale.

Results We received 105 responses (36\% response rate): 61\% (64) of providers chose IO/IO, 39\% (41) chose IO/TKI (figure 1). $78 \%(82)$ of oncologists were academic or disease-focused, 22\% (23) were general. Academic/disease-focused oncologists were significantly more likely to choose IO/IO (56/82, 68\%) than general oncologists $(8 / 23,35 \%), p=0.004$ (figure 2). Among those who chose $\mathrm{IO} / \mathrm{IO}$, the perceived main issue with IO/TKI was: long-term toxicities - 31\% (20), short-term toxicities - 28\% (18), less effective - 28\% (18), less convenient $8 \%$ (5). Among those who chose IO/TKI, the perceived main issue with $\mathrm{IO} / \mathrm{IO}$ was: short-term toxicities - 43\% (17), less effective - 28\% (11), long-term toxicities - 15\% (6), and risk of death - $10 \%$ (4) (figure 3). $88 \%$ (92) of all providers would be comfortable enrolling patients into a phase III trial comparing IO/IO vs. IO/TKI. We found no associations between therapy chosen by a provider and participation as PI in a trial of $\mathrm{IO} / \mathrm{IO}$ or $\mathrm{IO} / \mathrm{TKI}$, or receipt of outside funding from an IO/IO or IO/TKI company.
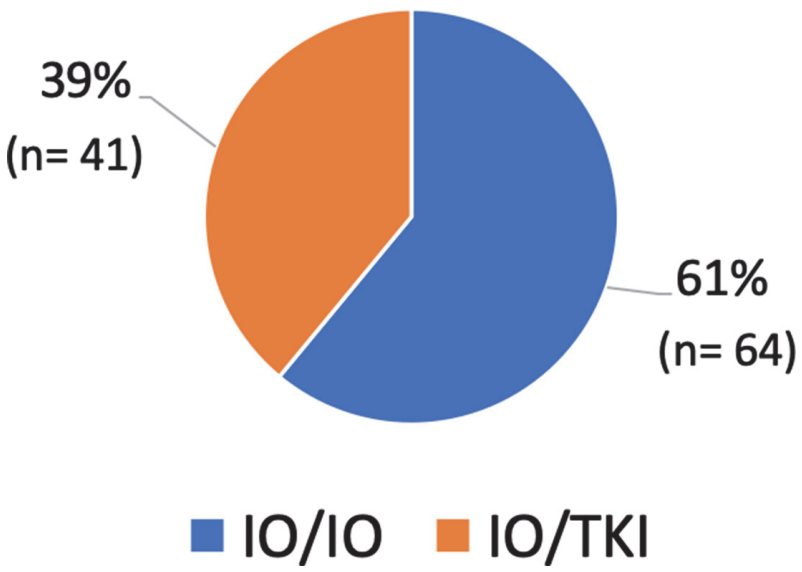

Abstract 629 Figure 1 Choice of therapy for patient scenario: I0/I0 vs. IO/TKI

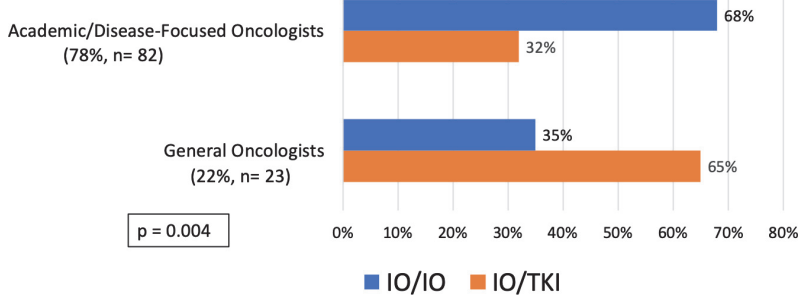

Abstract 629 Figure 2 Association between type of practice and choice of therapy

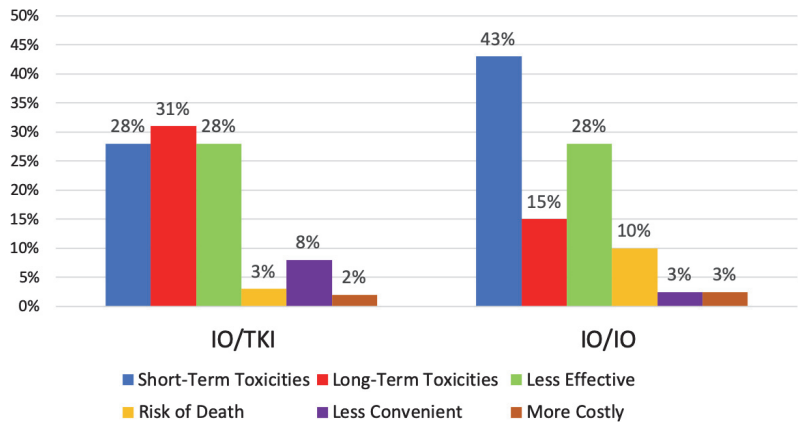

Abstract 629 Figure 3 Perceived main issue with IO/TKI or IO/IO as per oncologists who chose the alternate treatment

Conclusions In response to a representative patient scenario of intermediate-risk RCC, $61 \%$ of providers chose IO/IO, 39\% chose IO/TKI. There was a significant association between type of practice and choice of therapy, with academic/diseasefocused oncologists being more likely to choose IO/IO. The vast majority of oncologists would be comfortable enrolling patients into a phase III trial comparing IO/IO vs. IO/TKI, demonstrating equipoise in the community regarding this question and providing support for such a trial.

\section{REFERENCES}

1. Motzer RJ, Tannir NM, McDermott DF. Nivolumab plus Ipilimumab versus Sunitinib in Advanced Renal-Cell Carcinoma. N Engl J Med 2018;378(14):1277-1290.

2. Rini BI, Plimack ER, Stus V. Pembrolizumab plus Axitinib versus Sunitinib for advanced Renal-Cell Carcinoma. N Engl J Med 2019;380(12):1116-1127.

3. Choueiri TK, Powles T, Burotto M. Nivolumab plus Cabozantinib versus Sunitinib for advanced Renal-Cell Carcinoma. N Engl J Med 2021;384(9):829-841.

4. Motzer R, Alekseev B, Rha SY. Lenvatinib plus Pembrolizumab or Everolimus for advanced renal cell Carcinoma. N Engl J Med 2021;384(14):1289-1300.

Ethics Approval This study was approved by the IRB at The University of Chicago Biological Sciences Division/University of Chicago Medical Center. The study ID is: IRB20-1570.

http://dx.doi.org/10.1136/jitc-2021-SITC2021.629 